\title{
The Vascular Smooth Muscle $\alpha$-Actin Gene Is Reactivated during Cardiac Hypertrophy Provoked by Load
}

\author{
Fiona M. Black, ${ }^{\star *}$ Sharon E. Packer, ${ }^{\star \star}$ Thomas G. Parker, ${ }^{* \neq}$ Lloyd H. Michael, ${ }^{\star \|}$ \\ Robert Roberts, ${ }^{* 5}$ Robert J. Schwartz," and Michael D. Schneider**8\| \\ ${ }^{*}$ Molecular Cardiology Unit, Departments of ${ }^{\ddagger}$ Medicine, ${ }^{8}$ Cell Biology, and "Molecular Physiology \\ and Biophysics, Baylor College of Medicine, Houston, Texas 77030
}

\begin{abstract}
Cardiac hypertrophy triggered by mechanical load possesses features in common with growth factor signal transduction. A hemodynamic load provokes rapid expression of the growth factor-inducible nuclear oncogene, c-fos, and certain peptide growth factors specifically stimulate the "fetal" cardiac genes associated with hypertrophy, even in the absence of load. These include the gene encoding vascular smooth muscle $\alpha$-actin, the earliest $\alpha$-actin expressed during cardiac myogenesis; however, it is not known whether reactivation of the smooth muscle $\alpha$-actin gene occurs in ventricular hypertrophy. We therefore investigated myocardial expression of the smooth muscle $\alpha$-actin gene after hemodynamic overload. Smooth muscle $\alpha$-actin mRNA was discernible $24 \mathrm{~h}$ after coarctation and was persistently expressed for up to $30 \mathrm{~d}$. In hypertrophied hearts, the prevalence of smooth muscle $\alpha$-actin gene induction was 0.909 , versus 0.545 for skeletal muscle $\alpha$-actin $(P<0.05)$. Ventricular mass after $2 \mathrm{~d}$ or more of aortic constriction was more highly correlated with smooth muscle $\alpha$-actin gene activation ( $r$ $=0.852 ; P=0.0001)$ than with skeletal muscle $\alpha$-actin $(r$ $=0.532 ; P=0.009) ; P<0.0005$ for the difference in the correlation coefficients. Thus, smooth muscle $\alpha$-actin is a molecular marker of the presence and extent of pressure-overload hypertrophy, whose correlation with cardiac growth at least equals that of skeletal $\alpha$-actin. Induction of smooth muscle $\alpha$-actin was delayed and sustained after aortic constriction, whereas the nuclear oncogenes c-jun and junB were expressed rapidly and transiently, providing potential dimerization partners for transcriptional control by c-fos. (J. Clin. Invest. 1991. 88:15811588.) Key words: cardiac differentiation - gene expression • hypertension • leucine zipper • transcription factor
\end{abstract}

\section{Introduction}

Myocardial hypertrophy produced in response to a hemodynamic load entails myocyte growth by cell enlargement, rather than proliferation, together with complex but characteristic

A preliminary report of this research was presented in abstract form at the Keystone Symposium, Molecular Mechanisms of Cardiac Growth and Hypertrophy, Keystone, CO, 24-31 January 1991 (J. Cell. Physiol. 15C:176.)

Address correspondence to Dr. Michael D. Schneider, Molecular Cardiology Unit, Baylor College of Medicine, One Baylor Plaza, Room 506C, Houston, TX 77030. 1991 .

Received for publication 13 March 1991 and in revised form 21 June

J. Clin. Invest.

(c) The American Society for Clinical Investigation, Inc.

$0021-9738 / 91 / 11 / 1581 / 08 \$ 2.00$

Volume 88, November 19.91, 1581-1588 changes in the expression of numerous cardiac-specific genes (1-3). A hallmark of this regulatory event is selective activation of the genes encoding protein isoforms ordinarily associated with the embryonic or fetal ventricle, including atrial natriuretic factor (4), $\beta$-tropomyosin (4), atrial myosin light chain (5), and the prototypes for this transition, $\beta$ myosin heavy chain (6-8) and skeletal muscle $\alpha$-actin $(4,8,9)$. Thus, hypertrophy provoked by load in adult myocardium recapitulates, at least in part, the embryonic program observed during cardiac development. Homologies between load-induced hypertrophy and growth factor signalling pathways have been suggested. First, a corresponding ensemble of fetal cardiac genes is upregulated in vitro in the absence of load after treatment of neonatal rat cardiac myocytes with basic fibroblast growth factor $(\mathrm{FGF})^{1}$ or transforming growth factor $\beta-1(\mathrm{TGF} \beta)(10,11)$; at least a subset of these genes can be evoked by other trophic factors including norepinephrine (12) and endothelin (13). Second, the rapid and transient induction of the nuclear oncogenes, c-myc and c-fos, after hemodynamic load $(4,14,15)$ also parallels signalling events evoked in cardiac myocytes by serum (16), FGFs (17), and other agonists $(13,18)$.

Given the induction of skeletal $\alpha$-actin mRNA by basic FGF, it was notable that acidic FGF, by contrast, suppressed the skeletal $\alpha$-actin gene in cardiac myocytes $(10,11)$. Basic and acidic FGF exerted antithetical, reciprocal effects on skeletal $\alpha$-actin transcription, via the proximal 202 nucleotides of 5 -flanking sequence, and acidic FGF also suppressed the transcription of cardiac $\alpha$-actin (11). Despite disparate effects on cardiac expression of the striated muscle $\alpha$-actins, acidic FGF otherwise evoked responses quite similar to basic FGF, including upregulation of vascular smooth muscle $\alpha$-actin (10), the earliest $\alpha$-actin expressed during cardiac myogenesis (19-21). Development of myocardium in the chick is heralded by the expression of smooth muscle $\alpha$-actin transcripts in cardiac mesoderm, before formation of the definitive tubular heart (19). This precedes the sequential activation of cardiac and skeletal $\alpha$-actin genes, which supplant the smooth muscle isoform later in ontogeny, and cardiac $\alpha$-actin is the predominant actin transcript in adult myocardium. Analogously, in the rat heart, smooth muscle $\alpha$-actin is expressed at an equivalent embryonic stage, and persists at decreasing levels until shortly after birth $(20,21)$. Adult rat cardiac myocytes reexpress smooth muscle $\alpha$-actin, during culture in growth factor-rich media (22). Interestingly, in humans, skeletal $\alpha$-actin gene expression increases throughout development and is the predominant $\alpha$-actin transcript in both normal and diseased cardiac muscle (23). Investigations to date have not tested the prediction that the smooth

1. Abbreviations used in this paper: $\mathrm{FGF}$, fibroblast growth factor; $\mathrm{LV}$, left ventricle; SRE, serum response element; TGF $\beta$, transforming growth factor $\beta$. 
muscle $\alpha$-actin gene might be reactivated as part of the generalized fetal phenotype during hypertrophy produced by load.

Notwithstanding evidence that c-myc (24) and c-fos (25) proteins recognize specific DNA targets and participate in transcriptional control, the logical inference that c-fos mediates growth or fetal gene expression provoked by pressure overload has not been proven mechanistically. A second restriction to this hypothesis is that sequence recognition by c-fos is potentiated through formation of heterodimers with proteins of the jun protooncogene family, whose prototypes are c-jun and jun $\mathrm{B}(25,26)$. The expression $(27,28)$ and regulatory properties $(29,30)$ of c-jun and junB each differ, providing selective transcriptional activity to the fos/jun dimers formed in various biological contexts. One target for negative regulation by fos/jun is a decanucleotide serum response element (SRE) in the c-fos promoter itself $(31,32)$; the SRE is induced by various serum peptides including both basic and acidic FGF $(33,34)$. Homologous elements within the skeletal muscle $\alpha$-actin gene mediate basal expression in skeletal (35-37) and cardiac (34) myocytes, and the proximal SRE is activated selectively in cardiac muscle by basic FGF, but not acidic FGF (34). However, it is unknown whether one or more of the obligatory dimerization partners for c-fos are expressed in adult rat myocardium or are induced during cardiac hypertrophy, as are other immediate-early genes.

Consequently, the aims of this study were: (a) to establish if vascular smooth muscle $\alpha$-actin, which is upregulated in cultured cardiac myocytes in tandem with other fetal cardiac genes, is induced in vivo as a component of the fetal phenotype triggered by mechanical load; $(b)$ if so, to determine which of the $\alpha$-actin genes was more highly correlated with production of ventricular hypertrophy; $(c)$ to ascertain whether genes encoding the required dimerization partners for c-fos might be upregulated in the ventricle after aortic constriction; and $(d)$ to demonstrate whether the kinetics for induction of c-jun, junB, or both were compatible with their postulated role mediating the induction of fetal cardiac genes after mechanical load.

\section{Methods}

Animals and surgical procedures. Adult male Sprague-Dawley rats $(250-300 \mathrm{~g})$ were anesthetized with sodium pentobarbital $\left(30 \mathrm{mg} \mathrm{kg}^{-1}\right.$, i.p.) and subjected to a sham operation $(n=47)$ or suprarenal aortic constriction of the abdominal aorta $(n=51)$, using a blunt 21-gauge needle to establish the diameter of the ligature (14). The degree of constriction was selected on the basis of preliminary studies, to induce moderate cardiac hypertrophy and minimize the likelihood of confounding variables such as acute cardiac failure. The sham procedure for control rats included placement of a loosely tied ligature at the identical position. Rats were subsequently killed at intervals of $0 \mathrm{~h}-30$ d. The left ventricle (LV) (left ventricular free wall and interventricular septum) was dissected free of the atria and right ventricle. Hypertrophy was calculated from the ratio of left ventricular mass/body mass normalized to that of control rats killed at the same stage ([LV/body $\div \mathrm{LV}_{\text {sham }} /$ body $\left.\left._{\text {sham }}\right]-1\right)$ and was defined operationally as a ratio $>2.4$ $\times 10^{-3}$.

RNA preparation and analysis. Total left ventricular RNA was isolated by the guanidium thiocyanate-phenol-chloroform method (38) and quantitated by spectrophotometry. Aliquots $(15 \mu \mathrm{g})$ of denatured RNA were size-fractionated by formaldehyde gel electrophoresis and transferred to nylon membranes. Hybridization probes for cardiac, skeletal muscle, and smooth muscle $\alpha$-actin were isoform-specific synthetic oligonucleotides derived from 3 '-untranslated sequences, as previously described $(10,16)$. Hybridization probes for c-jun and junB were full- length murine cDNAs (28). Oligonucleotide probes were 5 -labelled with $\left[\gamma^{32} \mathrm{P}\right] \mathrm{ATP}(5,000 \mathrm{Ci} / \mathrm{mmol})$ using T4 polynucleotide kinase, to a

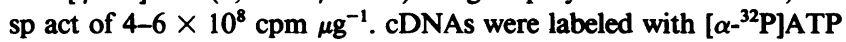
$(3,000 \mathrm{Ci} / \mathrm{mmol})$ by the random hexamer method (39). RNA blot hybridization was performed as described (40). Blots were washed for 45 $\mathrm{min}$ in $6 \times \mathrm{SSC}$ at room temperature, then $20 \mathrm{~min}$ in $6 \times \mathrm{SSC} / 1 \% \mathrm{SDS}$ at $42^{\circ} \mathrm{C}$ for oligonucleotides and $50^{\circ} \mathrm{C}$ for cDNAs. Blots were exposed to XAR-2 film (Eastman Kodak Co., Rochester, NY) at $-70^{\circ} \mathrm{C}$ with intensifying screens. Autoradiograms were subsequently quantitated by scanning densitometry and normalized on the basis of $28 \mathrm{~S}$ rRNA to correct for RNA loading. For each gene studied, results following aortic constriction or sham operation are expressed as relative mRNA concentrations, normalized to the sham-operated controls at $\mathbf{0 ~} \mathbf{~}$.

Statistical procedures. Experimental results were compared by the unpaired two-tail $t$ test for two-group comparisons, and Scheffe's multiple comparison test for single factor analysis of variance, using a signifcance level of $P<0.05$. Sham-operated animals did not vary significantly with time and were pooled for the comparisons, as in related investigations (7).

\section{Results}

Smooth muscle and skeletal muscle $\alpha$-actin genes are coordinately induced during myocardial hypertrophy. After the sham procedure, the ratio of $\mathrm{LV}$ mass to body mass in control animals was $2.19 \pm 0.024 \times 10^{-3}(n=34)$ and did not vary systematically with time. Under the moderate conditions used here to avoid potentially confounding effects of cardiac failure, suprarenal aortic constriction induced relatively mild ventricular hypertrophy $(0.14 \pm 0.036$, range $0-0.45)$ at $4-30 \mathrm{~d}$ (Fig. 1), with a prevalence of 0.48 . Overall mortality $(0.33)$ was less than reported previously in more severe models of load $(7,14)$. The mean left ventricular mass/body mass was not increased beyond that of the sham-operated control group at $\leq 2 \mathrm{~d}$, and was first increased at $4 \mathrm{~d}\left(2.53 \pm 0.226 \times 10^{-3} ; n=4 ; P\right.$ $=0.0015$ ). Taken together, the mean LV/body mass ratio was $2.49 \pm 0.078 \times 10^{-3}$ at 4 or more days after aortic constriction ( $n=19 ; P=0.0001$ ), and was maintained at a ratio of $\sim 2.5$ $\times 10^{-3}$ from 9 to $30 \mathrm{~d}(P=0.0008,0.0001,0.0057$ at 9,15 , and $30 \mathrm{~d}$, respectively).

To establish whether plasticity of cardiac gene expression was provoked by the relatively conservative constriction used here, we first tested for induction of the skeletal $\alpha$-actin gene, associated with fetal myocardium. Representative data are

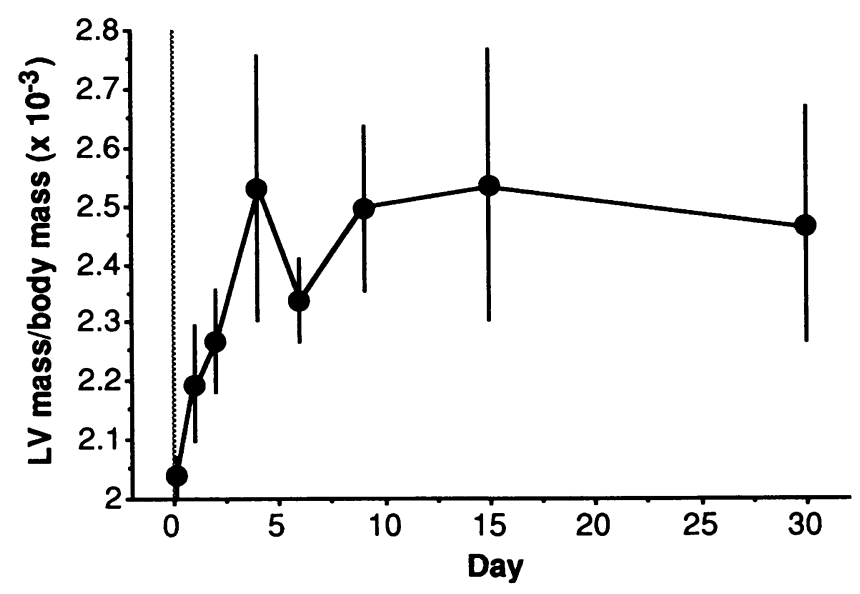

Figure 1. Induction of cardiac hypertrophy after aortic constriction. Results shown are the mean $\pm \operatorname{SE}(n=3$ or 4$)$ at each interval tested. 


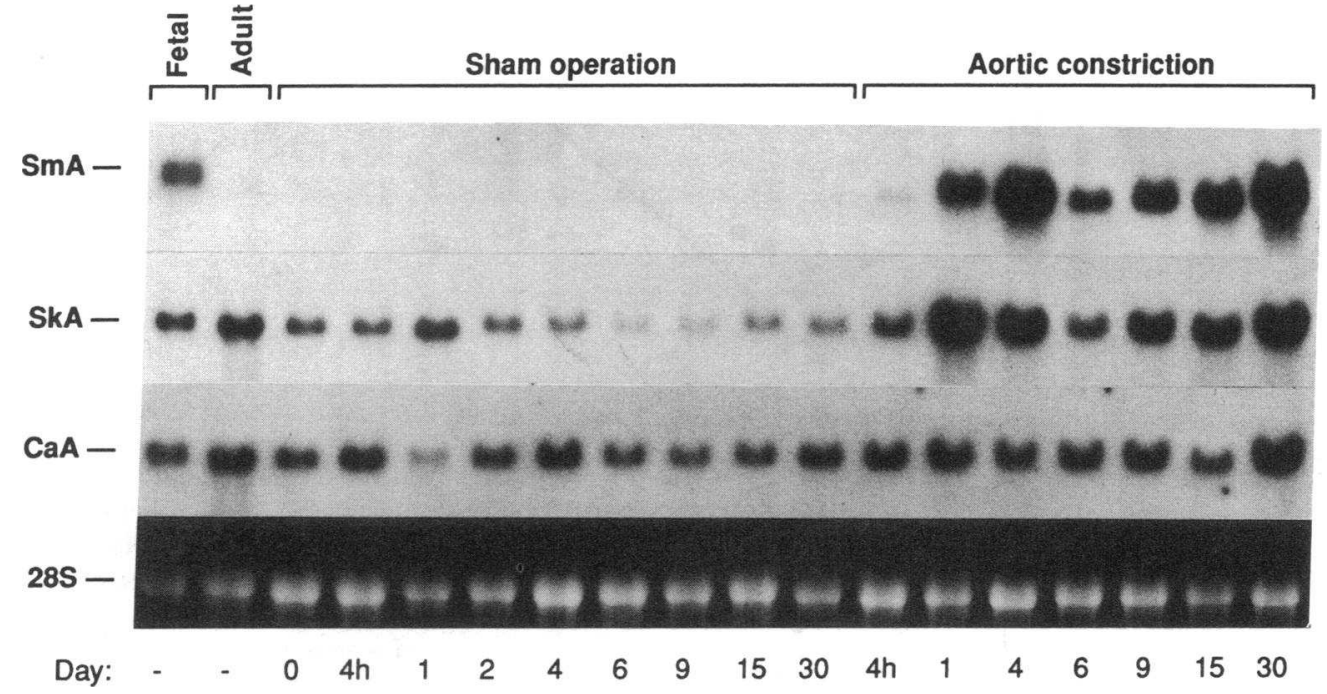

shown in Fig. 2, and four independent experiments (each comprising sham-operated and constricted animals at eight intervals after surgery) are summarized in Fig. 3, $A-B$. Despite the variable and modest degree of hypertrophy resulting from the ligature, induction of the skeletal $\alpha$-actin gene after aortic constriction differed significantly from levels of expression seen in the sham-operated controls. Overall, steady-state expression of the skeletal $\alpha$-actin gene after aortic constriction was induced $4.43 \pm 0.87 \times(n=31 ; P=0.0002)$, relative to the sham procedure $(1.17 \pm 0.21 \times ; n=34)$. The sham-operated animals did not differ significantly from unoperated controls, did not vary over time, and were pooled for the subsequent statistical analysis $(4,9)$. By contrast to the ventricular growth response, upregulation of skeletal $\alpha$-actin mRNA was evident within $24 \mathrm{~h}$ (7.61 $\pm 3.1 \times ; n=4 ; P=0.0001)$ and was maximal at $48 \mathrm{~h}$ (9.12 $\pm 3.8 \times ; n=4 ; P=0.0001)$, similar to previous studies (4, 9). Expression of skeletal $\alpha$-actin transcripts persisted at lower abundance, at later intervals after coarctation. After $2 \mathrm{~d}$ or more of aortic constriction, the skeletal $\alpha$-actin gene remained induced by at least 3 standard deviations in 6 of the 11 hearts with concurrent hypertrophy (mean, $7.33 \pm 1.7 \times$ ), versus only 1 of the 12 without hypertrophy (mean, 1.73 $\pm 0.30 \times ; P$ $=0.0032$ ). Thus, induction of the skeletal $\alpha$-actin gene, to levels exceeding those observed in embryonic myocardium, was specifically associated with the presence of ventricular hypertrophy. By contrast, aortic constriction evoked no statistically significant change in expression of the cardiac $\alpha$-actin gene (Fig. 3, $E-F$ ).

From the fact that TGF $\beta$ and basic FGF reactivate the smooth muscle $\alpha$-actin gene, as well as skeletal $\alpha$-actin, in cultured cardiac muscle cells $(10,11)$ we hypothesized that cardiac hypertrophy might be associated with reinduction of the smooth muscle $\alpha$-actin gene in vivo. Using an oligonucleotide specific for smooth muscle $\alpha$-actin, derived from the 3 '-untranslated region, smooth muscle $\alpha$-actin transcripts were readily identified in the 14-d embryonic heart under standard conditions (15 $\mu \mathrm{g}$ per lane), as well as in adult myocardium after aortic constriction. By contrast, little or no smooth muscle $\alpha$-actin mRNA was detected in normal adult rat ventricular myocardium or in sham-operated control hearts $(n=34)$ (Figs. 2 and $3, C-D$ ). To facilitate more accurate estimates of smooth
Figure 2. Smooth muscle $\alpha$ actin and skeletal muscle $\alpha$ actin gene expression are coordinately induced during cardiac hypertrophy. Results of a representative Northern blot hybridization study are shown. Each autoradiogram was exposed for $2 \mathrm{~d}$. For reference, $\alpha$-actin expression in embryonic 14-d and adult rat hearts is indicated at the left. Ethidium-bromide stained $28 \mathrm{~S}$ ribosomal RNA is shown below the figure. (See Fig. 3 for summary of four independent experiments.) $S m A$, smooth muscle $\alpha$-actin; $S k A$, skeletal muscle $\alpha$-actin; $\mathrm{CaA}$, cardiac $\alpha$-actin. muscle $\alpha$-actin gene induction after aortic constriction, samples containing up to $40 \mu \mathrm{g}$ per lane of RNA from sham-operated adult rat myocardium initially were compared with 14-d embryonic myocardium, which could be readily evaluated (Fig. 4). Smooth muscle $\alpha$-actin mRNA in the 14-d embryonic heart was 12.7-fold more abundant than in sham-operated adult myocardium. Consequently, to compare smooth muscle $\alpha$-actin gene activation after aortic constriction relative to sham-operated adult heart, hybridization signals first were normalized to a reference sample of embryonic day 14 myocardium and were then multiplied by 12.7 .

Overall, the mean level of smooth muscle $\alpha$-actin mRNA induction after aortic constriction was $9.01 \pm 2.36 \times(n=31 ; P$ $=0.0002$ ). Smooth muscle $\alpha$-actin mRNA was not significantly elevated $4 \mathrm{~h}$ after coarctation, but had increased $7.31 \pm 5.0 \times$ by $24 \mathrm{~h}(n=4 ; P=0.0001)$. Smooth muscle $\alpha$-actin mRNA remained highly expressed $2 \mathrm{~d}$ after aortic constriction (up to 20.5X; mean, 11.5 $\pm 5.1 \times ; n=4 ; P=0.0001$ ) and at $4 \mathrm{~d}$ (up to $35.7 \times$; mean, $11.5 \pm 8.4 ; n=4 ; P=0.0005$ ). High levels of expression were noted at up to $30 \mathrm{~d}(9 \mathrm{~d}: 6.5 \pm 4.1 ; n=4 ; P$ $=0.0001 ; 15 \mathrm{~d}: 23.3 \pm 12.2 ; n=3 ; P=0.0001 ; 30 \mathrm{~d}: 9.79 \pm 9.79$; $n=4 ; P=0.0017)$. Although the observed kinetics are potentially affected by the prevalence of hypertrophy elicited at differing intervals, smooth muscle $\alpha$-actin mRNA was induced no more than $23 \times$ at $6 \mathrm{~d}$, even in hypertrophied hearts, whereas the smooth muscle $\alpha$-actin gene was activated up to 44 and $40 \times$ at 15 and $30 \mathrm{~d}$, respectively. Similarly, the skeletal muscle $\alpha$-actin gene was induced no more than $3 \times$ at $6 \mathrm{~d}$, versus up to 11.5 and $14.2 \times$ at 15 and $30 \mathrm{~d}$. The transient decline in smooth muscle and skeletal muscle $\alpha$-actin mRNA accumulation at $6 \mathrm{~d}$ is not explained by the absence of induced hypertrophy at this stage (cf. Fig. 1). A comparable transient decrease occurs in $\beta$ myosin heavy chain mRNA (7).

At two or more days of coarctation, where it becomes feasible to correlate gene activation with the presence or absence of induced growth, smooth muscle $\alpha$-actin gene induction in hypertrophied hearts was $22.1 \pm 4.03 \times(n=11)$ versus $0.59 \pm 0.40 \times(n=12)$ in hearts which did not hypertrophy after coarctation $(n=12 ; P=0.0001)$. Activation of the smooth muscle $\alpha$-actin gene occurred in 10 of the 11 hypertrophied hearts (range, 8.9-43.8 $\times$ ), versus 2 of 12 without hypertrophy 
A

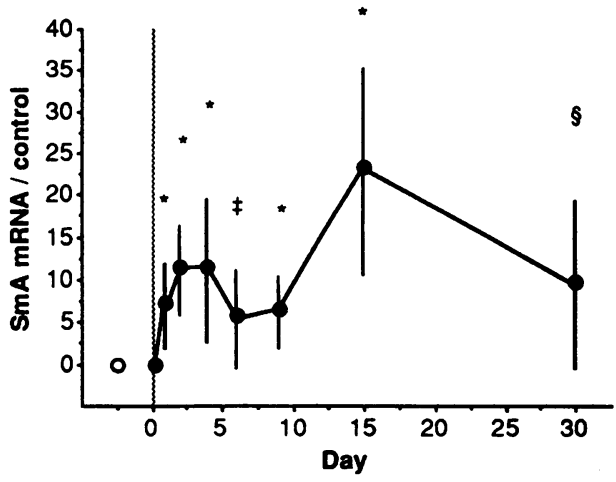

C

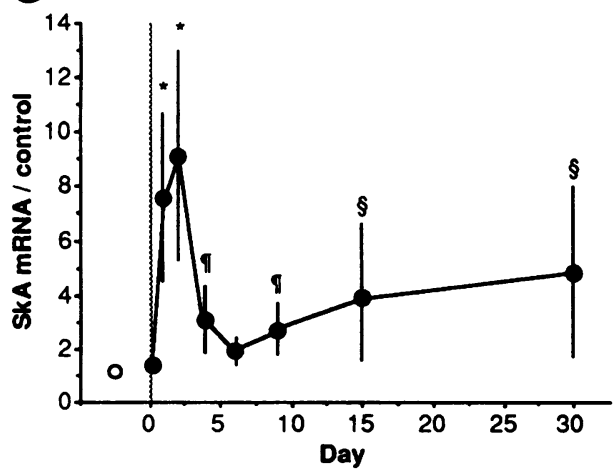

E

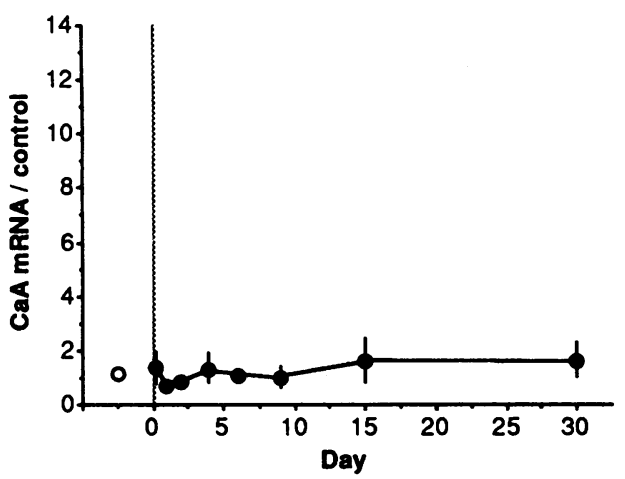

B

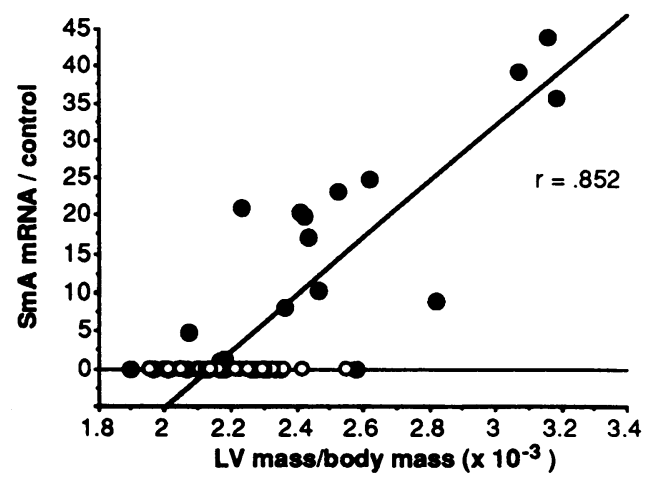

D

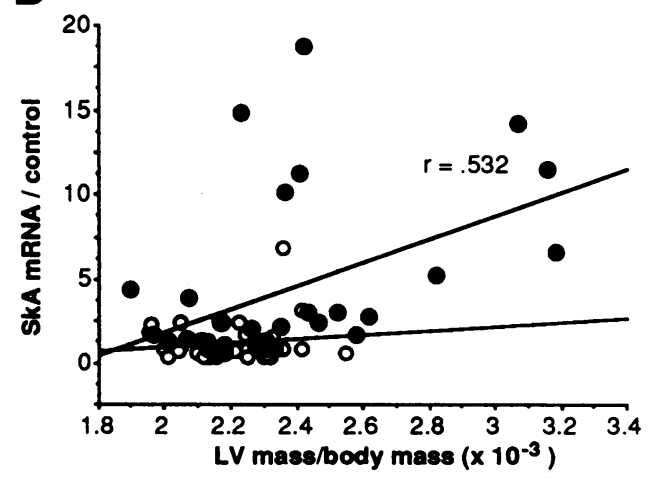

$\mathbf{F}$

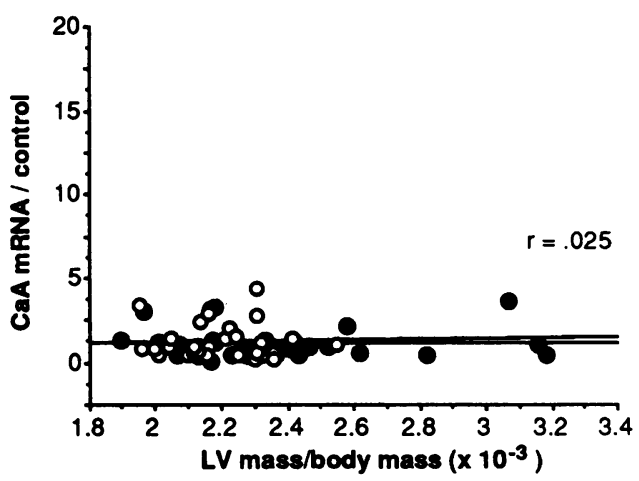

Figure 3. $(A, B)$ Smooth muscle $\alpha$-actin; $(C, D)$ skeletal muscle $\alpha$-actin; and $(E, F)$ cardiac $\alpha$ actin gene expression after coarctation. $(A, C, E)$ Kinetics of $\alpha$-actin gene induction. $O$, sham operation; $\bullet$, aortic constriction. Results are expressed as the mean $\pm \operatorname{SE}(n=3$ or 4$)$, relative to sham operated controls at $0 \mathrm{~h}$. The sham operation value used for statistical comparisons, shown at the left in each panel, denotes the mean \pm SE of 34 samples, comprising two to four independent controls at each of the timepoints tested. ${ }^{*} P \leq 0.0001 ;{ }^{8} P$ $\leq 0.005 ;{ }^{\ddagger} P \leq 0.001 ;{ }^{1} P \leq 0.05$. Student's unpaired two-tail $t$ test was used to calculate $P$ values, where analysis of variance was significant by Scheffe's test. ( $B$, $D, F)$ Correlation of $\alpha$-actin gene induction with the extent of ventricular hypertrophy. Individual values are shown for each animal subjected to $(0)$ sham operation $(n=34)$ or $(\bullet)$ aortic constriction $(n=31)$. Correlation coefficients were derived from the animals subjected to coarctation for two or more days.

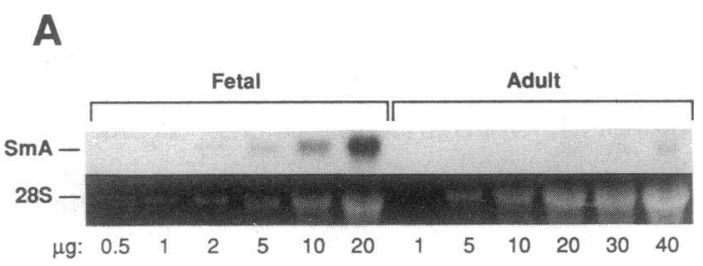

B

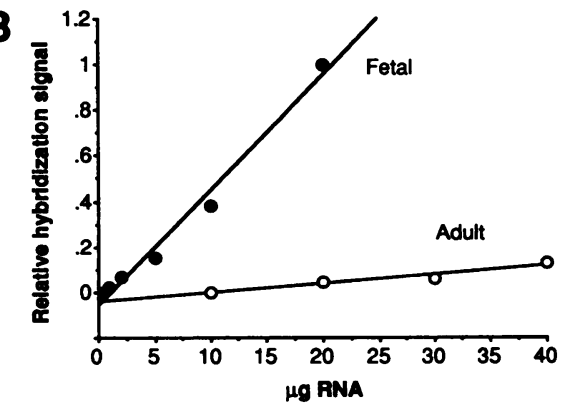

Figure 4. Comparison of smooth muscle $\alpha$-actin gene expression in embryonic 14-d and sham-operated adult myocardium. $(A)$ Northern blot hybridization, using $0.5-40 \mu \mathrm{g}$ RNA. Ethidium-bromide stained $28 \mathrm{~S}$ ribosomal RNA is shown for reference. $(B)$ Hybridization signal versus $\mu \mathrm{g}$ RNA. The hybridization signals were linear with RNA over the range shown, with correlation coefficients of 0.992 and 0.961 in (๑) embryonic and (o) adult myocardium, respectively. 


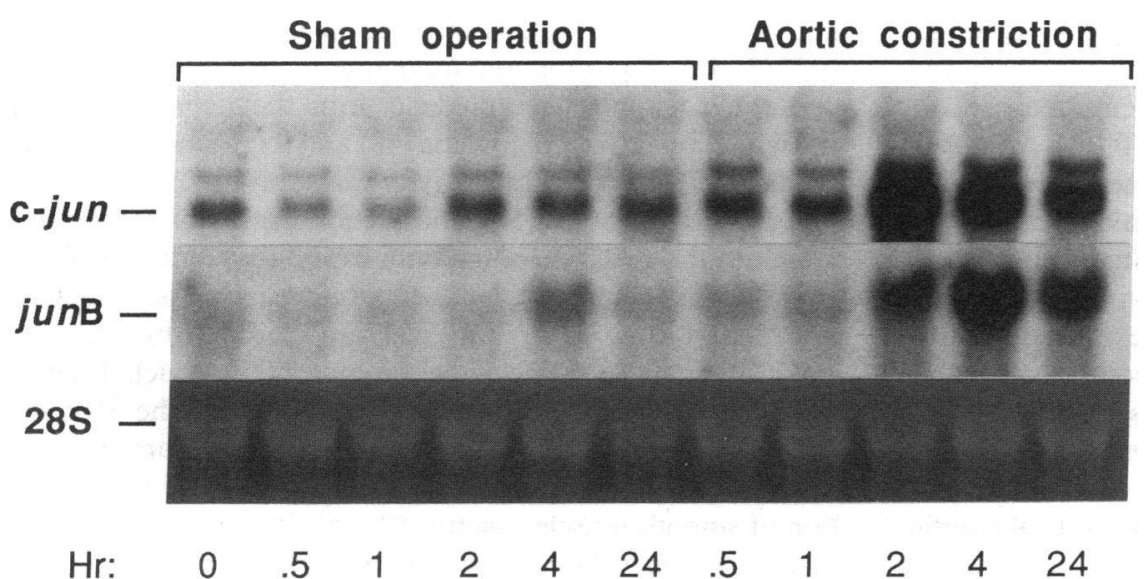

Figure 5. Induction of c-jun and junB after aortic constriction. Results of a representative Northern blot hybridization are shown. The c-jun and junB autoradiograms were exposed for two and three days, respectively. Ethidiumbromide stained 28S ribosomal RNA is shown below the figure. (See Fig. 6 for summary of four independent experiments.) despite coarctation (range, 1.4-4.7 $\times$ ). As expected, induction of the skeletal $\alpha$-actin gene was associated with hypertrophy; however, the prevalence of skeletal muscle $\alpha$-actin gene induction in hypertrophy was only 0.545 , versus 0.909 for the smooth muscle $\alpha$-actin gene $(P<0.05$, by McNemar's test for paired categorical data). Although a positive linear correlation was found between the LV mass/body mass ratio and observed levels of skeletal $\alpha$-actin mRNA $(r=0.532 ; n=23 ; P=0.009)$, ventricular growth and skeletal $\alpha$-actin gene activity were not uniformly concordant. By contrast, the increase in ventricular mass was correlated more suggestively with the degree of smooth muscle $\alpha$-actin activation $(r=0.852 ; n=23 ; P$ $=0.0001$ ); the correlation coefficient was comparable to that previously observed for $\beta$ myosin heavy chains (7). This difference in the correlation coefficients was significant by Fisher's $z$ score, with $P<0.0005$. There was no significant relation between cardiac $\alpha$-actin expression and ventricular mass ( $r$ $=0.025 ; n=23 ; P=0.9115$ ). Thus, smooth muscle $\alpha$-actin is a marker of both the presence and extent of ventricular hypertrophy, whose correlation with cardiac growth, under the conditions tested, at least equals that of skeletal $\alpha$-actin.

The c-jun and junB transcription factors are induced consecutively after coarctation. To ascertain whether one or more members of the jun multigene family are induced in myocardium following mechanical load and, if so, whether their activation is highly congruent, left ventricular RNA samples at intervals after aortic constriction were analyzed for expression of c-jun and junB (Figs. 5 and 6). Basal expression of c-jun (2.5 and $3.2 \mathrm{~kb})$ and jun $\mathrm{B}(2.0 \mathrm{~kb})$ was detected, in agreement with previous results in adult mouse myocardium (26). After the sham operation, neither c-jun $(1.29 \pm 0.20 \times)$ nor junB $(1.42 \pm 0.16 \times ; n=18)$ was upregulated significantly. After coarctation, c-jun mRNA increased within $60 \mathrm{~min}(2.23 \pm 0.53 \times$; $n=4 ; P=0.0291)$, and remained elevated for up to $24 \mathrm{~h}(2 \mathrm{~h}$ : $3.34 \pm 1.32 ; n=3 ; P=0.0018 ; 4$ h: $3.15 \pm 0.43 \times ; n=3 ; P$ $=0.0001 ; 24 \mathrm{~h}: 2.69 \pm 0.64 \times ; n=4 ; P=0.0032)$. Overall, c-jun mRNA increased $2.64 \pm 0.30 \times(n=17 ; P=0.0001)$. Thus, c-jun is induced after aortic constriction with kinetics at least as rapid as reported for other immediate-early genes such as c-fos and $c-m y c(4,15)$.

Although junB was upregulated at least as highly as c-jun, its kinetics of accumulation were relatively delayed. Steadystate junB mRNA levels did not increase significantly relative to the unoperated controls, until $2 \mathrm{~h}$ after coarctation (2.54 $\pm 1.05 \times ; n=3 ; P=0.0244)$. JunB mRNA continued to accumulate at $4 \mathrm{~h}(4.56 \pm 2.01 \times ; n=3 ; P=0.0005)$ and was maximal at $24 \mathrm{~h}(9.90 \pm 3.76 \times ; n=4 ; P=0.0001)$. By contrast, in quiescent fibroblasts, junB and c-jun were induced with parallel kinetics, within $30 \mathrm{~min}$ of serum stimulation (26). As the identical hybridization filters were used to detect c-jun and junB, the disparity in their kinetics of induction is neither a spurious consequence of RNA loading nor an artifact of variance in the production of hypertrophy. Neither c-jun nor junB remained upregulated after two or more days of coarctation (not shown).

\section{Discussion}

Smooth muscle $\alpha$-actin gene induction corroborates the fetal phenotype in pressure overload hypertrophy. The experiments reported here demonstrate that reactivation of the vascular smooth muscle $\alpha$-actin gene, the first $\alpha$-actin expressed during cardiac myogenesis, accompanies cardiac hypertrophy produced by coarctation. These findings contribute to the inference that the pattern of cardiac-specific gene expression in overloaded myocardium resembles, in many ways, a fetal program (1-9, 41). ("Hypertrophy recapitulates ontogeny.") In addition, our results at least partially resolve two interesting ambiguities concerning smooth and skeletal muscle $\alpha$-actin

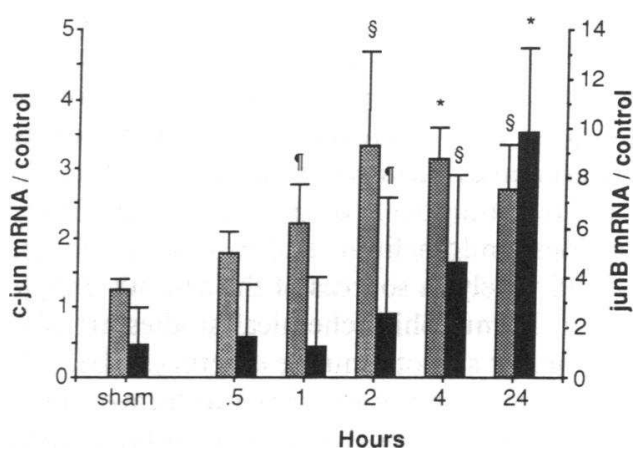

Figure 6. c-jun and junB are induced consecutively after mechanical load. Results are expressed as the mean $\pm \operatorname{SE}(n=3$ or 4$)$, relative to sham operated controls at $0 \mathrm{~h}$. The sham operation value used for statistical comparisons, shown at the left in each panel, denotes the mean \pm SE of 22 samples, comprising three to four independent controls at each of the time-points tested. ${ }^{*} P \leq 0.0001 ;{ }^{8} P \leq 0.005{ }^{\prime}{ }^{\prime} P$ $\leq$ 0.05. $P$ values were calculated as for Fig. 3. Grey, c-jun; black, junB. 
gene expression in cardiac hypertrophy. First, fibroblast growth factors and type $\beta$ transforming growth factor selectively induce an ensemble of fetal cardiac genes in cultured cardiac myocytes, including smooth muscle $\alpha$-actin $(10,11)$. Although the overall similarity was noted between these growth factor effects and the fetal phenotype associated with hypertrophy, it was conjectural whether smooth muscle $\alpha$-actin gene induction would in fact accompany cardiac growth in vivo. Second, despite the usefulness of skeletal $\alpha$-actin for investigations of trophic signalling mechanisms in cardiac cells both in vitro (10$12,42)$ and in vivo $(8,9,43)$, skeletal $\alpha$-actin is expressed erratically in diseased human myocardium, at levels that do not differ significantly from normal values (23). The inability to detect an association between hypertrophy and skeletal $\alpha$-actin induction in myocardial disease is consistent, conceivably, with the failure of ventricular growth and skeletal $\alpha$-actin mRNA levels to concur quantitatively even under more controlled conditions. Conversely, the greater correlation between hypertrophy and reactivation of the smooth muscle $\alpha$-actin gene advances the case for examining smooth muscle $\alpha$-actin gene expression during cardiac hypertrophy in humans. Basal expression of skeletal $\alpha$-actin mRNA in myocardium exceeded the minimal levels observed previously by others in Wistar rats $(4,9)$; we detect similar levels of skeletal $\alpha$-actin mRNA in both Sprague-Dawley and Wistar rats from the vendor used, but cannot exclude differences in housing conditions (44) as a factor contributing to expression in the unoperated and shamoperated controls.

Plasticity of smooth muscle $\alpha$-actin gene expression. Two limitations of this study are shared with the published data concerning upregulation of the skeletal $\alpha$-actin gene during cardiac hypertrophy. First, the structural and functional effects of reinducing either fetal $\alpha$-actin gene in adult myocardium remain to be shown. For example, no phenotypic consequences are evident from a reduplication of the $5^{\prime}$ end of the cardiac $\alpha$-actin gene, which results in high-level expression of skeletal $\alpha$-actin in Balb/C mice (45). Consequently, we and others have postulated that the fetal cardiac genes which are coordinately induced during hypertrophy might share regulatory mechanisms in common, rather than homeostatic value (1-3). However, even single point mutations in actin can measurably alter cross-bridge kinetics (46), and a systematic comparison of $\alpha$ actin function by in vitro motility assays has not yet been performed. Second, subsequent experiments are required to establish whether the smooth muscle $\alpha$-actin transcripts result in accumulation of the corresponding protein. Reactivation of smooth muscle $\alpha$-actin gene expression to levels exceeding those in the fetal heart makes it less probable that induction has occurred in only a minor component of the myocardium. However, coronary arteries, endothelium, and cardiac fibroblasts must be excluded ultimately as sources of the smooth muscle $\alpha$-actin mRNA (47). Immunohistochemical studies are also required to define whether smooth muscle $\alpha$-actin can become incorporated into the sarcomeres of adult myocardium or, alternatively, is confined to with stress fibers, as in cultured adult cardiac myocytes (22).

Smooth muscle $\alpha$-actin gene induction is congruent with an autocrine or paracrine model of pressure-overload hypertrophy. We previously demonstrated upregulation of fetal cardiac genes, including smooth and skeletal muscle $\alpha$-actin, in cardiac myocytes stimulated with TGF $\beta$ or basic FGF $(10,11)$. Thus, growth factor-dependent mechanisms might potentiate, modu- late, or sustain the signals initiated in myocardium by load itself $(3,41)$. The proposed autocrine or paracrine model of cardiac hypertrophy gains credence from the inconsistent relationship of load to cardiac mass (48) and fetal gene expression $(8,49)$. Undefined trophic activity was found in myocardium after pressure overload (50), and aortic constriction is reported to induce the genes encoding both TGF $\beta$ (51) and basic FGF (52). For skeletal $\alpha$-actin, basal expression in cardiac myocytes and induction by basic FGF both are mediated by a CC[A/ $\mathrm{T}]_{6} \mathrm{GG}$ element in the proximal promoter (34), which displays sequence similarity and cross-competition with the SRE for growth factor induction of c-fos $(33,36,53)$. Canonical SREs have likewise been implicated in basal tissue-specific transcription of smooth muscle $\alpha$-actin $(54,55)$. It is presently conjectural, however, whether this family of regulatory elements is crucial to the induction of either smooth muscle or skeletal muscle $\alpha$-actin after mechanical load.

The oncogene signalling hypothesis. The transcription factors c-myc and c-fos are rapidly and transiently induced in the heart by pressure overload $(4,14,15)$ or increased coronary perfusion pressure (56). In cultured ventricular cells expression of c-fos is provoked by diverse agonists or interventions whose effects resemble hypertrophy in vivo, including FGFs (Parker, T. G., F. M. Black, and M. D. Schneider, unpublished results), endothelin-1 (13), and passive stretch (57). Taking these findings together with more mechanistic data in other systems for the role of nuclear oncogenes, we and others have proposed that inducible transcription factors such as fos and myc might couple mechanical load to long-term changes in ventricular growth and gene expression $(1-4,13,15,18,41,57)$. Since fos proteins function as heterodimers, we have verified here that genes encoding two potential dimerization partners, c-jun and jun $\mathrm{B}$, are expressed in adult rat myocardium, and ascertained that these putative mediators are expressed with appropriately rapid kinetics, preceding growth and induction of fetal cardiac genes. Despite similar DNA-binding specificity, the transcriptional activities of c-jun and junB differ $(29,30)$. The delayed accumulation of junB after coarctation, relative to c-fos and c-jun, is consistent with the reported role of $j u n B$ as an inhibitor of c-jun activity. Any causal inferences related to hypertrophy must be provisional, however, in the absence of functional studies utilizing oncogene expression vectors or, conversely, interdicting trophic signal transduction within cardiac muscle cells. Candidates for such studies also include junD and four members of the fos protein family-fra-1, fra-2, fos B, and an alternatively spliced form of $f o s \mathrm{~B}, \Delta f o s \mathrm{~B}$, which inhibits both transactivation and transrepression by fos and jun (58). Additional permutations of jun heterodimers are generated via other classes of leucine zipper proteins $(59,60)$.

Dilemmas confronting any attempt to explain long-term changes in myocardial gene expression on the basis of immediate-early response genes include the very transient expression of the postulated mediators and, more importantly, the absence of canonical fos/jun (AP-1) binding sites in many of the cardiac genes which are coregulated during hypertrophy. Transcriptional control of c-fos itself provides a useful counterexample. The target for transrepression of the fos promoter by c-fos is not an AP-1 site, but rather the unrelated $\operatorname{SRE}(31,32)$, and mutant fos proteins defective for DNA binding transrepress effectively (31). Through protein-protein interactions involving other classes of transcription factors, fos and jun proteins modulate gene expression indirectly (61). Consequently, 
it is reasonable to postulate that fos/jun complexes produced after a mechanical load might regulate smooth muscle and skeletal muscle $\alpha$-actin transcription, along with other cardiac genes that lack a fos/jun binding site. As a final caveat, $\beta$-adrenergic agonists induce both c-fos and c-jun but not cardiac-specific genes (62) (cf. [63]); thus, increased expression of these two oncogenes (at least, at the RNA level) need not suffice to cause the transcriptional program of hypertrophy. Conversely, posttranslational modifications might induce DNA-binding and transactivation (64) or transrepression (65) by preexisting AP-1.

In summary, aortic coarctation reactivates the vascular smooth muscle $\alpha$-actin gene in myocardium. Upregulation of the smooth muscle $\alpha$-actin gene was demonstrated previously in neonatal cardiac myocytes stimulated by transforming and fibroblast growth factors, which produce a generalized fetal phenotype resembling that seen after mechanical load. Among the potential signalling molecules coupling mechanical load to long-term changes in gene expression, aortic constriction provokes not only the transcription factor, c-fos, but two of its dimerization partners, c-jun and junB, whose functional properties differ. These results establish that smooth muscle $\alpha$-actin is a molecular marker of the presence and extent of ventricular hypertrophy, and reveal additional congruities between growth factor signal transduction and hypertrophy triggered by load. These investigations also suggest that functional fos/jun dimers should exist in overloaded myocardium, and identify candidate genes for disruption of trophic signalling pathways in myocardial cells.

\section{Acknowledgments}

We are grateful to P. Jackson, G. Liedtke, D. May, and L. AbdelMaguid for technical assistance, to $S$. West for statistical expertise, and to E. Olson for the c-jun and junB cDNAs and his reading of the manuscript.

Supported by grants to M. D. Schneider (R01-HL39141, P50HL42267), R. Roberts (P50-HL42267), L. H. Michael (P50HL42267), and R. J. Schwartz (R01-HL38401, P50-HL42267) from the National Institutes of Health. F. M. Black and T. G. Parker are Fellows of the American Heart Association-Bugher Foundation Center for Molecular Biology of the Cardiovascular System. T. G. Parker is a Fellow of the Medical Research Council of Canada. L. H. Michael is supported by the DeBakey Heart Center. M. D. Schneider is an Established Investigator of the American Heart Association.

\section{References}

1. Nadal-Ginard, B., and V. Mahdavi. 1989. Molecular basis of cardiac performance: plasticity of the myocardium generated through protein isoform switches. J. Clin. Invest. 84:1693-1700.

2. Schneider, M. D., and T. G. Parker. 1990. Cardiac myocytes as targets for peptide growth factors. Circulation. 81:1443-1456.

3. Parker, T. G., and M. D. Schneider. 1991. Growth factors, proto-oncogenes, and plasticity of the cardiac phenotype. Annu. Rev. Physiol. 53:179-200.

4. Izumo, S., B. Nadal-Ginard, and V. Mahdavi. 1988. Proto-oncogene induction and reprogramming of cardiac gene expression produced by pressure overload. Proc. Natl. Acad. Sci. USA. 85:339-343.

5. Rovner, A. S., E. M. McNally, and L. A. Leinwand. 1990. Complete cDNA sequence of rat atrial myosin light chain-1: patterns of expression during development and with hypertension. Nucleic Acids Res. 18:1581-1586.

6. Lompre, A.-M., K. Schwartz, A. d'Albis, N. L. Thiem, G. Lacombe, and B. Swynghedauw. 1979. Myosin isoenzyme distribution in chronic heart overload. Nature (Lond.). 282:105-107.

7. Izumo, S., A. M. Lompre, R. Matsuoka, G. Koren, K. Schwartz, B. NadalGinard, and V. Mahdavi. 1987. Myosin heavy chain messenger RNA and protein isoform during cardiac hypertrophy: interaction between hemodynamic and thyroid hormone-induced signals. J. Clin. Invest. 79:970-977.
8. Schiaffino, S., J. L. Samuel, D. Sassoon, A. M. Lompre, I. Garner, F. Marotte, M. Buckingham, L. Rappaport, and K. Schwartz. 1989. Nonsynchronous accumulation of $\alpha$-skeletal actin and $\beta$-myosin heavy chain mRNAs during early stages of pressure-overload-induced cardiac hypertrophy demonstrated by in situ hybridization. Circ. Res. 64:937-948.

9. Schwartz, K., D. de la Bastie, P. Bouveret, P. Oliviero, S. Alonso, and M. Buckingham. 1986. $\alpha$-Skeletal muscle actin mRNAs accumulate in hypertrophied adult rat hearts. Circ. Res. 59:551-555.

10. Parker, T. G., S. E. Packer, and M. D. Schneider. 1990. Peptide growth factors can provoke "fetal" contractile protein gene expression in rat cardiac myocytes. J. Clin. Invest. 85:507-514.

11. Parker, T. G., K.-L. Chow, R. J. Schwartz, and M. D. Schneider. 1990. Differential regulation of skeletal $\alpha$-actin transcription in cardiac muscle by two fibroblast growth factors. Proc. Natl. Acad. Sci. USA. 87:7066-7070.

12. Bishopric, N., P. C. Simpson, and C. P. Ordahl. 1987. Induction of the skeletal $\alpha$-actin gene in $\alpha_{1}$-adrenoreceptor-mediated hypertrophy of rat cardiac myocytes. J. Clin. Invest. 80:1194-1199.

13. Shubeita, H. E., P. M. McDonough, A. N. Harris, K. U. Knowlton, C. C. Glembotski, J. H. Brown, and K. R. Chien. 1990. Endothelin induction of inositol phospholipid hydrolysis, sarcomere assembly, and cardiac gene expression in ventricular myocytes. A paracrine mechanism for myocardial cell hypertrophy. $J$. Biol. Chem. 265:20555-20562.

14. Mulvagh, S. L., L. H. Michael, M. B. Perryman, R. Roberts, and M. D. Schneider. 1987. A hemodynamic load in vivo induces cardiac expression of the cellular oncogene, c-myc. Biochem. Biophys. Res. Commun. 147:627-636.

15. Komuro, M., M. Kurabayashi, F. Takaku, and Y. Yazaki. 1988. Expression of cellular oncogenes in the myocardium during the developmental stage and pressure-overload hypertrophy of the rat heart. Circ. Res. 62:1075-1079.

16. Ueno, H., M. B. Perryman, R. Roberts, and M. D. Schneider. 1988. Differentiation of cardiac myocytes following mitogen withdrawal exhibits three sequential stages of the ventricular growth response. J. Cell Biol. 107:1911-1918.

17. Black, F. M., T. G. Parker, L. H. Michael, R. Roberts, and M. D. Schneider. 1991. The c-jun and junB proto-oncogenes are induced in myocardium by a hemodynamic load in vivo and fibroblast growth factors in vitro. $J$. Cell. Biochem. 15C:176. (Abstr.)

18. Starksen, N. F., P. C. Simpson, N. Bishopric, S. R. Coughlin, W. M. F Lee, J. Escobedo, and L. T. Williams. 1986. Cardiac myocyte hypertrophy is associated with c-myc protooncogene expression. Proc. Natl. Acad. Sci. USA. 83:8348-8350.

19. Ruzicka, D. L., and R. J. Schwartz. 1988. Sequential activation of $\alpha$-actin genes during avian cardiogenesis: vascular smooth muscle $\alpha$-actin gene transcripts mark the onset of cardiomyocyte differentiation. J. Cell Biol. 107:25752586.

20. Woodcock-Mitchell, J., J. J. Mitchell, R. B. Low, M. Kieny, P. Sengel, L. Rubbia, O. Skalli, B. Jackson, and G. Gabbiani. 1988. Alpha-smooth muscle actin is transiently expressed in embryonic rat cardiac and skeletal muscles. Differentiation. 39:161-166.

21. Sawtell, N. M., and J. L. Lessard. 1989. Cellular distribution of smooth muscle actins during mammalian embryogenesis: expression of the alpha-vascular but not the gamma-enteric isoform in differentiating striated myocytes. J. Cell Biol. 109:2929-2937.

22. Eppenberger-Eberhard, T. M., I. Flamme, V. Kurer, and H. M. Eppenberger. 1990. Reexpression of alpha-smooth muscle actin isoform in cultured adult rat cardiomyocytes. Dev. Biol. 139:269-278.

23. Boheler, K. R., L. Carrier, D. de la Bastie, P. D. Allen, M. Komadja, J.-J. Mercadier, and K. Schwartz. 1991. Skeletal actin mRNA increases in the human heart during ontogenic development and is the major isoform of control and failing adult hearts. J. Clin. Invest. 88:323-330.

24. Luscher, B., and R. N. Eisenman. 1990. New light on myc and myb: 1 Myc. Genes \& Dev. 4:2025-2035.

25. Curran, T., and B. R. Franza. 1990. Fos and jun: the AP-1 connection. Cell. 55:395-397.

26. Hirai, S. I., R.-P. Ryseck, F. Mechta, R. Bravo, and M. Yaniv. 1989 Characterization of junD: a new member of the jun proto-oncogene family. EMBO (Eur. Mol. Biol. Organ.) J. 8:1433-1439.

27. Bartel, D. P., M. Sheng, L. F. Lau, and M. E. Greenberg. 1989. Growth factors and membrane depolarization activate distinct programs of early response gene expression: dissociation of fos and jun induction. Genes \& Dev. 3:304-313

28. Li, L., J.-S. Hu, and E. N. Olson. 1990. Different members of the jun proto-oncogene family exhibit distinct patterns of expression in response to type $\beta$ transforming growth factor. J. Biol. Chem. 265:1556-1562.

29. Chiu, R. P. Angel, and M. Karin. 1989. Jun-B differs in its biological properties from, and is a negative regulator of, c-Jun. Cell. 59:979-986.

30. Schütte, J., J. Viallet, M. Nau, S. Segal, J. Fedorko, and J. Minna. 1989. Jun-B inhibits and c-fos stimulates the transforming and trans-activating activities of c-jun. Cell. 59:987-997.

31. Lucibello, F. C., C. Lowag, M. Neuberg, and R. Müller. 1989. Trans-repression of the mouse c-fos promoter: a novel mechanism of fos-mediated transregulation. Cell. 59:999-1007.

32. Rivera, V. M., M. Sheng, and M. E. Greenberg. 1990. The inner core of 
the serum response element mediates both the rapid induction and subsequent repression of c-fos transcription following serum stimulation. Genes Dev. 4:255268.

33. Treisman, R. 1986. Identification of a protein-binding site that mediates transcriptional response of the c-fos gene to serum factors. Cell. 46:567-574.

34. Parker, T. G., K.-L. Chow, R. J. Schwartz, and M. D. Schneider. 1991. A proximal segment of the skeletal $\alpha$-actin promoter, resembling the c-fos serum response element, is induced selectively in cardiac muscle by basic, but not acidic, fibroblast growth factor. Clin. Res. 39:191a. (Abstr.)

35. Muscat, G. E. O., T. A. Gustafson, and L. Kedes. 1988. A common factor regulates expression of the cardiac and skeletal actin genes in muscle cells. $\mathrm{Mol}$. Cell. Biol. 8:4120-4133.

36. Walsh, K. 1989. Cross-binding of factors to functionally different promoter elements in c-fos and skeletal actin genes. Mol. Cell. Biol. 9:2191-2201.

37. Chow, K. L., and R. J. Schwartz. 1990. A combination of closely associated positive and negative cis-acting promoter elements regulates transcription of the skeletal alpha-actin gene. Mol. Cell. Biol. 10:528-538.

38. Chomczynski, P., and N. Sacchi. 1987. Single-step method of RNA isolation by acid guanidinium thiocyanate-phenol-chloroform extraction. Anal. Bio chem. 162:156-159.

39. Feinberg, A. P., and B. Vogelstein. 1983. A technique for radiolabeling DNA endonuclease fragment to high specific activity. Anal. Biochem. 132:6-13.

40. Sambrook, J., E. F. Fritsch, and T. Maniatis. 1989. Molecular Cloning: A

Laboratory Manual. Cold Spring Harbor Laboratory, Cold Spring Harbor, NY

41. Schneider, M. D., R. Roberts, and T. G. Parker. 1991. Modulation of cardiac genes by mechanical stress: the oncogene signalling hypothesis. Mol. Biol. Med. In press.

42. Komuro, I., Y. Katoh, T. Kaida, Y. Shibazaki, M. Kurabayashi, E. Hoh, F. Takaku, and Y. Yazaki. 1991. Mechanical loading stimulates cell hypertrophy and specific gene expression in cultured rat cardiac myocytes. J. Biol. Chem. 266:1265-1268.

43. Winegrad, S., C. Wisnewsky, and K. Schwartz. 1990. Effect of thyroid hormone on the accumulation of mRNA for alpha skeletal and cardiac actin in hearts from normal and hypothysectomized rats. Proc. Natl. Acad. Sci. USA. 87:2456-2460.

44. Winegrad, S., C. Wisnewsky, P. Bouveret, and K. Schwartz. 1991. Brief perturbation of the environment produces prolonged changes in gene expression of rat hearts. Biophys. J. 59:55a.

45. Garner, I., D. Sassoon, J. Vandekerchkove, S. Alonso, and M. E. Buckingham. 1989. A developmental study of the abnormal expression of $\alpha$-cardiac and $\alpha$-skeletal actins in the striated muscle of a mutant mouse. Dev. Biol. 134:236-245.

46. Drummond, D. R., M. Peckham, J. C. Sparrow, and D. C. S. White. 1990 Alteration in crossbridge kinetics caused by mutations in actin. Nature (Lond.) 348:440-442.

47. Kapanci, Y., S. Burgan, G. G. Pietra, B. Conne, and G. Gabbiani. 1990. Modulation of actin isoform expression in alveolar myofibroblasts (contractile interstitial cells) during pulmonary hypertension. Am. J. Physiol. 136:881-889.

48. Schulman, S. P., J. L. Weiss, L. C. Becker, S. O. Gottlieb, K. M. Woodruff, M. L. Weisfeldt, and G. Gerstenblith. 1990. The effects of antihypertensive therapy on left ventricular mass in elderly patients. $N$. Engl. J. Med. 322:1350-1356.

49. Matsubara, H., J. Yamamoto, Y. Hirata, Y. Mori, S. Oikawa, and M. Inaada. 1990. Changes of atrial natriuretic peptide and its messenger RNA with development and regression of cardiac hypertrophy in renovascular hypertensive rats. Circ. Res. 66:176-184.
50. Hammond, G. L., E. Wieben, and C. L. Markert. 1979. Molecular signals for initiating protein synthesis in organ hypertrophy. Proc. Natl. Acad. Sci. USA. 76:2455-2459.

51. Villareal, F. J., and W. H. Dillmann. 1991. Changes in gene expression of extracellular matrix proteins with myocardial hypertrophy. J. Cell Biochem. 15C:174. (Abstr.)

52. Chiba, M., S. Sakai, M. Nakata, and H. Toshima. 1990. The role of basic fibroblast growth factor in myocardial hypertrophy. Circulation. 82:III-761. (Abstr.)

53. Gustafson, T. A., and L. Kedes. 1989. Identification of multiple proteins that interact with functional regions of the human cardiac alpha-actin promoter. Mol. Cell. Biol. 9:3269-3283.

54. Carroll, S. L., D. J. Bergsma, and R. J. Schwartz. 1988. A 29-nucleotide DNA segment containing an evolutionarily conserved motif is required in cis for cell-type-restricted repression of the chicken alpha-smooth muscle actin gene core promoter. Mol. Cell. Biol. 8:241-250.

55. Reddy, S., K. Ozgur, M. Lu, W. Chang, S. R. Mohan, C. C. Kumar, and H. E. Ruley. 1990. Structure of the human smooth muscle alpha-actin gene: analysis of a cDNA and 5' upstream region. J. Biol. Chem. 265:1683-1687.

56. Bauters, C., J. M. Moalic, J. Bercovici, C. Mouas, R. R. Emanoil, S. Schiaffino, and B. Swynghedauw. 1988. Coronary flow as a determinant of c-myc and c-fos proto-oncogene expression in an isolated adult rat heart. J. Mol. Cell. Cardiol. 20:97-101.

57. Komuro, I., T. Kaida, Y. Shibazaki, M. Kurabayashi, Y. Katoh, E. Hoh, F. Takaku, and Y. Yazaki. 1990. Stretching cardiac myocytes stimulates protooncogene expression. J. Biol. Chem. 265:3595-3598.

58. Nakabeppu, Y., and D. Nathans. 1991. A naturally occurring truncated form of fosB that inhibits fos/jun transcriptional activity. Cell. 64:751-759.

59. Ivashkiv, L. B., C. L. Hsiou, C. J. Kara, W. W. Lamph, I. M. Verma, and L. H. Glimcher. 1990. mXBP/CRE-BP2 and c-Jun form a complex which binds to the cyclic AMP, but not to the 12-0-teradecanoylphorbol 13-acetate, response element. Mol. Cell. Biol. 10:1609-1621.

60. MacGregor, P. F., C. Abate, and T. Curran. 1990. Direct cloning of leucine zipper proteins: Jun binds cooperatively to the CRE with CRE-BP1. Oncogene. 5:451-458.

61. Yang-yen, H.-F., J.-C. Chambard, Y.-L. Sun, T. J. Schmidt, J. Drouin, and M. Karin. 1990. Transcriptional interference between c-jun and the glucocortoid receptor: Mutual inhibition of DNA binding due to direct protein-protein interaction. Cell. 62:1205-1215.

62. Iwaki, K., V. P. Sukhatme, H. E. Shubeita, and K. R. Chien. 1990. $\alpha$-and $\beta$-adrenergic stimulation induces distinct patterns of immediate early gene expression in neonatal rat myocardial cells: fos/jun expression is associated with sarcomere assembly; $E g r-1$ induction is primarily an $\alpha_{1}$-mediated response. $J$. Biol. Chem. 265:13809-13817.

63. Bishopric, N. H., and L. Kedes. 1991. Adrenergic regulation of the skeletal $\alpha$-actin gene promoter during myocardial cell hypertrophy. Proc. Natl. Acad. Sci. USA. 88:2132-2136.

64. Boyle, W. J., T. Smeal, L. H. K. Defize, P. Angel, J. R. Woodgett, M. Karin, and T. Hunter. 1991. Activation of protein kinase C decreases phosphorylation of c-Jun at sites that negatively regulate its DNA-binding activity. Cell. 64:573-584.

65. Ofir, R., V. J. Dwarki, D. Rashid, and I. M. Verma. 1990. Phosphorylation of the C-terminus of fos protein is required for transcriptional transrepression of the c-fos promoter. Nature (Lond.). 348:80-82. 